\title{
La producción de queso de cabra artesanal frente a la producción industrial: los crianceros de Río Hurtado y su experiencia en una planta quesera promovida por el Estado
}

LUIS PEZO ORELLANA

> Universidad de Chile, Santiago, Chile. luis_pezo@hotmail.com

Universidad de Valparaíso

Facultad de Arquitectura

Revista Márgenes

Espacio Arte Sociedad

La producción de queso de cabra artesanal frente a la

producción industrial: los crianceros de Río Hurtado y su

experiencia en una planta quesera promovida por el Estado

Septiembre 2016 Vol. 13 № 18

Páginas 7 a 16

ISSN elec. 0719-4463

ISSN imp. 0718-4034

Recepción: enero 2016

Aceptación: abril 2016

RESUMEN

La ganadería caprina es la actividad pecuaria más importante de la región de Coquimbo, Chile, configurando un particular modo de producción y de vida cuyo principal producto, el queso de cabra artesanal, es el sustento de miles de personas pertenecientes a familias crianceras.

En los años noventa y en la década siguiente, el Estado promovió emprendimientos asociativos para la producción industrial de queso de cabra pasteurizado, los cuales se desplegaron en proyectos de plantas queseras en diversas comunas de la región.

Este trabajo examina la experiencia de una planta quesera en la comuna de Río Hurtado, usando como principal fuente el testimonio de crianceros que participaron en ella. El análisis se articuló en tres ejes: a) los procesos participativos, b) las evaluaciones de los crianceros sobre su experiencia en la intervención y c) los efectos que esta experiencia ha tenido sobre sus propias perspectivas respecto al desarrollo rural. Los resultados permiten reflexionar sobre la interacción de las intervenciones de desarrollo con la cultura local y sobre la persistencia de la producción artesanal del queso de cabra.

PALABRAS CLAVE

desarrollo rural, sociedad civil, crianceros, producción artesanal de queso de cabra, pertinencia sociocultural

\section{Artisanal goat cheese's production against industrial production: the goat breeders of Río Hurtado and their experience in a cheese-making plant promoted by the state \\ ABSTRACT}

The goat breeding is the most important livestock activity in Coquimbo region, Chile, setting a particular mode of production and life, whose main product, the artisanal cheese goat, is the livelihood of thousands of goat breeder's families.

In the nineties and the following decade, the state promoted associative projects for industrial production of pasteurized goat cheese, which were deployed in cheese-making plants in various districts.

This paper examines the experience of a cheese-making plant in Rio Hurtado, using as main source the goat breeder's testimony who participated in it. The analysis was structured in three areas: a) the participatory processes, $b$ ) the assessments of goat breeders about their experience and c) the effects on their own perspectives on rural development. The results allow us to reflect about the interaction of development interventions with local culture and the persistence of artisanal goat cheese's production.

KEYWORDS

rural development, civil society, goat breeders, artisanal goat-cheese's production, sociocultural pertinence 
El presente artículo examina la experiencia de algunos crianceros (criadores de ganado caprino) de la comuna de Río Hurtado en una planta de producción de queso pasteurizado, a la cual pudimos aproximarnos en el marco de una investigación mayor, orientada al estudio de trayectorias de participación de la sociedad civil en el desarrollo rural (Pezo, 2010). De manera general, se busca comprender el impacto de las políticas e intervenciones de desarrollo desplegadas tras el fin de la dictadura en el sector rural, en relación a las perspectivas propias de la sociedad civil con respecto al desarrollo rural.

En este caso específico, la metodología utilizada se basó fundamentalmente en entrevistas a crianceros que participaron en la iniciativa, cuya información se articuló en tres ejes de análisis: a) los procesos participativos, b) las evaluaciones de los crianceros sobre su experiencia en la intervención y c) los efectos que esta experiencia ha tenido sobre sus propias perspectivas respecto al desarrollo rural y la producción artesanal de queso de cabra. En virtud de la riqueza de su aporte para el análisis, se incorporan algunos testimonios de los crianceros entrevistados.

\section{RELATO DE LA EXPERIENCIA}

A principios de los 90, tras el fin de la dictadura, la población rural de la región de Coquimbo figuraba en las estadísticas sociales entre las más pobres del país. A través de políticas sociales y de fomento productivo, el gobierno implementó programas en relación a lo social y lo agrícola, respectivamente, pero la producción caprina no fue abordada de manera sustancial en esos primeros años, pese a constituir la principal fuente de sustento de la mitad de la población rural de la región (Ramírez, 2003).

La gran mayoría de los crianceros practica una explotación tradicional de tipo extensiva, que involucra el pastoreo desplegado fundamentalmente en sectores de secano y de alta montaña y la elaboración artesanal de queso de cabra. Este sistema de producción pastoril ha producido, a través de las generaciones, modos de vida particulares que sin embargo han sido dinámicos y sensibles a los cambios económicos, sociales y ecológicos de la zona y el país ${ }^{1}$.

Las comunidades agrícolas y crianceros formaron asociaciones para buscar solución a sus problemas, pero su situación tocó fondo en el año 1992, cuando se produjo una conmoción mediática debido a intoxicaciones con queso artesanal de cabra, que provocó una crisis en el rubro, demandando el accionar de las autoridades. Stüdemann, en un trabajo etnográfico realizado en el año 2003 , lo relata de la siguiente manera:

En el año 1992 hubo un escándalo de proporciones que tuvo al queso de cabra como protagonista. Consumidores del producto lácteo sufrieron intoxicaciones por el mal estado del alimento, lo que causó mucho revuelo en la prensa de la época. Se habló de las precarias condiciones higiénicas en que estos quesos eran preparados, lo peligroso que resultaba su exposición al calor y se llamó a la población a no consumir este producto si era de carácter artesanal. El efecto comercial para los crianceros fue inmediato y desastroso. Bodegas de queso quedaron repletas; la abrupta disminución en la demanda llegó a fijar al kilo en 100 pesos (Stüdemann, 2003:20).

8 > Revista Márgenes No 18 Vol 13 > Septiembre 2016: 7 a 16 Facultad de Arquitectura > Universidad de Valparaíso
Los crianceros de Río Hurtado entrevistados para nuestro estudio también nos relatan aquella crisis, que dio pie a los proyectos para industrializar el queso de cabra en la región:

Hubo un tiempo que no se podían vender los quesos, no querían que vendiéramos queso de cabra (...), Y qué, en ese tiempo éramos tantos los cabreros que habíamos y hacíamos todos quesos y vivíamos de los quesos, entonces estábamos parados. (...) Y ahí nació esa idea de hacerles queseras a la gente (Participante de la quesera).

En aquel tiempo, la mayoría de los crianceros de Río Hurtado vendía sus quesos a un almacén de Pichasca, ya que era difícil venderlos directamente en Ovalle, por la mala calidad de los caminos y los escasos medios de transporte disponibles. Con la crisis, el almacén restringió la compra de quesos y quedaron muchos crianceros con el producto devaluado y sin tener dónde vender.

En medio de esta situación las autoridades regionales vieron el escenario propicio para impulsar la producción industrial de queso de cabra pasteurizado a través de proyectos asociativos de plantas queseras, cuyo planteamiento se orientaba a cumplir con las exigencias sanitarias, modernizar el rubro (producción más eficiente, a mayor escala, mayor rentabilidad e inserción en los mercados) y superar la pobreza rural del secano.

Las autoridades se reunieron con agrupaciones de comuneros y crianceros, con personal técnico y con otras instituciones para impulsar la creación de varias plantas queseras en la región. En Río Hurtado, a mediados de los 90 , las gestiones se realizaron a través del Instituto de Desarrollo Agropecuario (INDAP), que se coordinó con la asociación de crianceros que existía en la comuna para darle forma al proyecto. Luego de varias gestiones y trámites, en 1998 se constituye la Sociedad Agroindustrial Las Acacias de Río Hurtado S. A., con 18 socios crianceros de la comuna, poniéndose en marcha la primera experiencia de producción industrial de queso de cabra pasteurizado en Río Hurtado.

La planta quesera obtuvo financiamiento inicial a través de INDAP. Se hicieron capacitaciones, diagnósticos técnicos, se compraron equipos para la pasteurización y un camión con frigorífico para el traslado de la leche, que debía ser provista por los crianceros asociados. Se contrató personal para el cuidado y aseo de la planta, se hicieron vínculos con otras instituciones para la comercialización y se obtuvo la resolución sanitaria correspondiente.

Sin embargo, el funcionamiento de la empresa fue discontinuo y no exento de diversos problemas, entre ellos, el suministro no permanente de leche, el desfinanciamiento por los pagos a plazo de los quesos en el mercado, los altos costos de producción, problemas en las relaciones con los técnicos y entre los socios. Todos estos factores terminaron por generar problemas de rentabilidad y de organización interna que no se pudieron superar, determinando el fracaso de esta iniciativa, ocurriendo situaciones similares en otras plantas queseras de la región, provocando incluso el endeudamiento de los socios (Durston et al., 2005; Peña, 2006). Afortunadamente, en Río Hurtado los socios quedaron exentos de deudas. La maquinaria fue retirada por INDAP, y el edificio de la quesera fue abandonado sin mayor resguardo, sufriendo robos y destrozos en los años siguientes. De nuestras notas de campo en el año 2008, destacamos un fragmento que describe la situación del establecimiento, lo cual se complementa con la Figura $N^{\circ} 1$ :

Facultad de Arquitectura > Universidad de Valparaíso 
Desde un pequeño cerro contiguo a la aldea de Pichasca, el desmantelado inmueble de la quesera guarda silente los vestigios olvidados de la inversión y los ajetreos de hace algunos años; tras los vidrios rotos y las puertas sin cerrojos se encuentra una vitrina para quesos que no fue recuperada, y en el suelo lleno de polvo de uno de los compartimentos se hayan botados desordenadamente papeles y logotipos de la empresa que nunca salieron al mercado, y que visitantes anónimos han ido pegando en las paredes de azulejos blancos...

\section{SOBRE LOS PROCESOS DE PARTICIPACIÓN EN LA INTERVENCIÓN}

Las autoridades regionales se contactaron con dirigentes de asociaciones de crianceros para concertar los proyectos y convocar a los futuros socios de las queseras. La intención de las autoridades era absorber la mayor cantidad posible de personas en la iniciativa para obtener más impacto y asegurar el suministro de leche. El discurso que predominaba era que la conversión productiva desde lo artesanal a lo industrial era, ineluctablemente, la clave de la inserción exitosa en los mercados, y la solución al problema sanitario que representaba la producción de queso artesanal, el cual sería prontamente prohibido por la normativa de alimentos. Sin embargo, de alrededor de 150 miembros de la asociación, sólo 18 participaron del proyecto.

La motivación primordial de los crianceros que estuvieron a favor de participar en la industria era la de vender a buen precio el queso en un momento en que el rubro seguía deprimido a raíz de la crisis, pesando sobre el producto artesanal la amenaza explícita de su fin a través de la aplicación del Reglamento Sanitario de Alimentos, que finalmente entró en vigencia en el año 1998 (Ramírez, 2003). Por otra parte, el temor al endeudamiento y a la pérdida de bienes eran las principales motivaciones en contra de participar en este proyecto. En este juego de motivaciones, llama la atención que la principal emoción presente es el temor, ya que en este escenario discursivo, los crianceros fueron puestos en el filo de la navaja entre desaparecer con el queso artesanal (cesantía, pobreza, hambre) o arriesgarse con el queso pasteurizado (endeudamiento, pérdida de bienes, transformación). Al tener en cuenta que la mayoría de los crianceros optaría por continuar en la ruta tradicional, las autoridades ofrecieron facilidades tales como otorgar el capital inicial y apoyar las gestiones, pidiendo a los socios poner un número de animales a disposición de la quesera como única garantía para su funcionamiento.

La reducción de los riesgos fue eficaz para motivar a los crianceros a probar una nueva forma de producción que podía ser exitosa. Sin embargo, nuestro estudio indica que se trataba de una motivación instrumental, funcional a la adaptación de los crianceros a las supuestas nuevas condiciones del mercado, y no de una motivación sustantiva de los crianceros por industrializarse.

En la motivación instrumental, la población tiene una disposición favorable a participar, pero la intervención representa sólo de manera parcial sus intereses, necesidades y demandas, por lo tanto la intervención es vista instrumentalmente como un medio para alcanzar mejores situaciones o resolver algún problema, pero la finalidad propuesta no es compartida por la población o sólo parcialmente. En cambio, cuando hay motivación sustantiva, la población tiene una disposición favorable a la participación en una determinada intervención de desarrollo, ya que ésta representa sus intere-

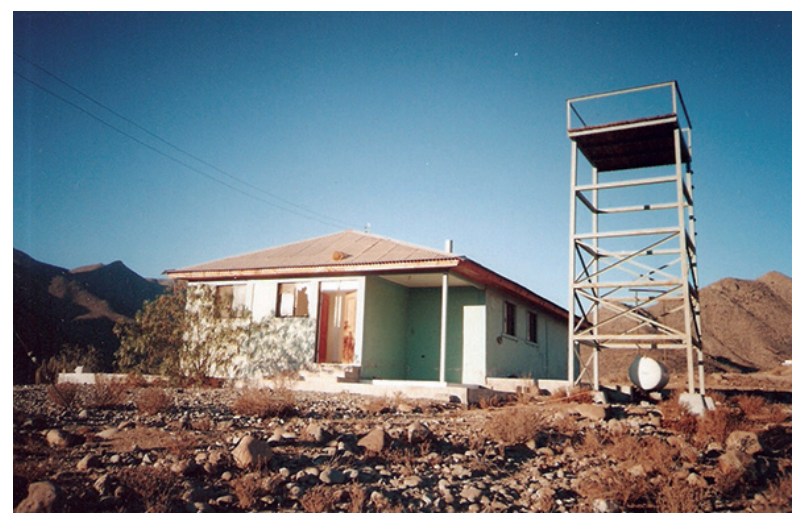

Figura 1. Edificio abandonado de la planta quesera de Pichasca, Río Hurtado. Fuente: Elaboración propia, 2008. 
ses, necesidades, demandas, y propone una finalidad deseada por la población hacia mejores situaciones. Ambos tipos de motivaciones tienen implicancias prácticas en la participación efectiva que se da en las intervenciones: la motivación instrumental produce por lo general una participación condicionada y débil, mientras que en la motivación sustantiva aumenta la probabilidad de generar una participación comprometida y proactiva (Pezo, 2010).

Se debe tener presente que en el caso que nos ocupa, la motivación a participar en la intervención fue inducida, primero por una amenaza, y luego por la instalación de una “oportunidad impuesta”2. Ante esta situación, la motivación no podía ser sino instrumental.

El análisis motivacional que hemos realizado nos permite inferir que en general los crianceros de la comuna no deseaban industrializar su rubro, sino que todo lo contrario: deseaban preservar sus modos de producción y de vida. Por esta razón la mayoría simplemente se marginó de esta iniciativa, pero quienes se incorporaron, la visualizaron como una oportunidad de adaptación en medio de un escenario desfavorable para el queso artesanal, cuyos riesgos fueron atenuados por el Estado. Se cumple con ello el planteamiento del antropólogo C. Ph. Kottak (1995:501), de acuerdo al cual en las sociedades campesinas (...) el objetivo de la estabilidad puede ser el principal motor del cambio (...) De esta forma, el cambio aparece como una estrategia de adaptación, necesaria para conservarse en un ambiente de cambio constante.

La flamante Sociedad Agroindustrial Las Acacias de Río Hurtado S.A estaba constituida por 16 hombres y 2 mujeres, dedicados al ganado caprino, residentes en distintas localidades de la comuna. Fueron asesorados muy cercanamente por INDAP, que gestionó capacitaciones impartidas por organismos técnicos y también contrató, a través de la planta quesera, a profesionales para guiar el proceso productivo. La sociedad fue presidida por el dirigente de la asociación de crianceros, que había participado en las reuniones con las autoridades cuando estos proyectos se gestaron, manteniendo un liderazgo no exento de problemas, pero que se mantuvo desde el principio hasta el fin de la experiencia.

Al comienzo, las decisiones relacionadas con la producción estuvieron muy influenciadas por INDAP y por el profesional contratado para dirigir los procesos, quien optó por elaborar un queso pasteurizado maduro, suscitándose la primera de varias discordancias con los crianceros, quienes abogaban por un queso más fresco. Las razones de ambos eran la rentabilidad en el mercado. Los socios cedieron ante los argumentos técnicos, pero el fracaso del queso maduro hizo que fueran los mismos crianceros los que asumieran la producción del queso pasteurizado.

Con aquella eventualidad, los crianceros lograron mayor autonomía en las decisiones de la producción y comercialización, sin dejar de contar con el apoyo de INDAP. Lo anterior nos permite señalar que la participación que se dio en esta intervención fue de tipo gestionaria, siguiendo la clasificación planteada por Raczynski y Serrano $(1998)^{3}$. Por cierto, la intención de las autoridades de gobierno era que estas empresas fueran sustentables e independientes luego de un plazo razonable de acompañamiento por parte de INDAP; en otras palabras, se intentó lo que Uphoff (1995:574) denomina "estrategia de la independencia apoyada", que plantea que para alcanzar algún grado de autonomía, las organizaciones deben movilizar recursos y no depender completamente de las redes externas.
En cuanto a la participación interna de los socios en la empresa, se dio lo que Contreras, Chamorro y Donoso (2004) denominan "clima organizacional delegativo": los socios delegaron en su presidente una gran cantidad de responsabilidades, entre ellas, hacerse cargo del proceso productivo y la vinculación con agentes del Estado y otros actores, limitándose a participar en las reuniones periódicas y en la venta de leche. No obstante, no todos asistían a las reuniones y no todos vendían leche. Esta parcialidad de la participación a nivel interno fue creando conflictos y desgastes en la organización.

Si bien los debates y las discrepancias entre los socios fueron asumidas como parte normal del desarrollo de la organización, en algunos casos los desacuerdos se transformaron en divergencias que amenazaban su estabilidad. Una de las divergencias entre los socios se dio por el hecho de que no todos vendían leche a la quesera, por lo tanto los crianceros que estaban más alejados se veían menos beneficiados. La lejanía de algunos crianceros hizo, en varias oportunidades, difícil su asistencia a las reuniones o el cumplimiento de las diversas responsabilidades a las que se habían comprometido.

Los informantes entrevistados señalan que los socios de la quesera fueron reacios a realizar aportes y a asumir compromisos, que hubo desinterés y desvinculación con el proyecto, lo que fue, según tales testimonios, una de las principales causas de su fracaso:

Por ejemplo, a veces llegábamos a acuerdo de que los socios podían aportar un día para hacer economía, porque ya si había que hacer dentro de una semana o en dos días harto queso, deberían venir los mismos socios a ayudar, entonces unos se comprometían y después no venían, no cumplian, entonces ahí quedaba todo cojo, porque había que andar apurado buscando una persona, buscar a otro que pudiera trabajar en queso, porque todos no saben trabajar el queso, sobre todo para hacerlo, que quede lisito, darle el apriete que corresponde, cosas así (Dirigente criancero que participó en la quesera).

El fracaso más grande que tuvimos fuimos nosotros mismos, porque no fuimos aportadores, no aportamos. Entonces todos querían que les saliera todo gratis, y usted sabe que nadie lo va a hacer gratis. Hay que aportar, trabajar. Nosotros no teníamos una oficina, entonces cada socio debía pagar mil pesos para pagar la oficina, y sabe que ni eso los socios pagaban, creían que era mucha plata, entonces ¿cómo se puede echar a andar una cosa? Yo quedé de eso, se me pasaron como cien metros de la cabeza para arriba, entonces yo con instituciones no quiero nada. Nada, nada (Dirigente criancero que participó en la quesera).

El presidente de la sociedad, que había sido el más entusiasta de todos, terminó cansándose de asumir la mayoría de las responsabilidades en la gestión del proyecto. Stüdemann describe su situación en los últimos años de la planta quesera:

(...) es un criancero tradicional que está impulsando con mucho ímpetu la modernización de su producción. Pretende producir sistemáticamente quesos provenientes de leche pasteurizada (...) Pero no debemos olvidar que la quesera es un proyecto de 18 socios, 17 de los cuales, al parecer, no demuestran interés por hacer funcionar la pequeña industria. Es decir, tal vez estamos ante una excepción dentro de los crianceros de la zona (Stüdemann, 2003:23). 
De los testimonios anteriores se desprende que los crianceros asociados nunca lograron "apropiarse" de la iniciativa, salvo en el caso de su presidente, que adquirió habilidades para la producción de queso pasteurizado, para la gestión de la empresa y para relacionarse con otros actores. Su motivación y su disposición a asumir riesgos pueden estar relacionadas con el hecho que, de todos los socios, era el que más cabezas de ganado poseía y mantenía a disposición de la quesera, teniendo además una respetada y emergente trayectoria como criancero, lo cual parece ser un aspecto relevante de su liderazgo ${ }^{4}$.

En cuanto a las relaciones externas, el organismo gestor de esta intervención y el principal interlocutor de la sociedad agroindustrial era INDAP. Este organismo acompañó de principio a fin el proceso de intervención, sirviendo como contraparte del Estado y como entidad financiera, realizando diagnósticos y asesorías, otorgando facilidades al inicio y al final de la experiencia, poniendo a disposición personal técnico y gestionando capacitaciones. Sin embargo, hubo problemas con algunos técnicos de INDAP relativos a la discordancia en decisiones relevantes y también con respecto a actitudes de los profesionales que se dirigían a imponer sus criterios sin escuchar o conversar de manera adecuada con los crianceros.

INDAP no fue la única entidad externa con la cual se relacionaron los crianceros; también desarrollaron alianzas con organizaciones del sector privado. Una de estas experiencias, que no tuvo buenos resultados, fue la participación de la sociedad en una cooperativa formada en Ovalle para comerciar los quesos. Esta cooperativa, apoyada por autoridades de gobierno, era una buena idea para reactivar la comercialización de quesos y estabilizar el mercado del queso pasteurizado elaborado por las queseras de la región. No obstante, hubo problemas de "transparencia” en el manejo de los recursos que terminaron provocando su desmoronamiento.

Mejor suerte tuvieron los crianceros de Río Hurtado al asociarse con un Centro de Gestión Empresarial creado a través de un programa de INDAP, que entregaba asesoría de profesionales y apoyo para la comercialización a varias empresas asociativas de campesinos y crianceros de la provincia.

Cabe destacar que, si bien los crianceros de Río Hurtado no tuvieron problemas con este Centro de Gestión, otra de las plantas de la provincia tuvo serios conflictos con esta organización, incluyendo acusaciones de malversación de fondos, de contratos de trabajo adulterados, de uso de recursos para financiar campañas políticas entre otros aspectos señalados por Durston et al. (2005:123).

Evidentemente, este tipo de experiencias negativas en el marco de una intervención del Estado genera desconfianzas en la población afectada respecto de los proyectos de desarrollo y de la formación de redes con agentes externos.

\section{EVALUACIONES DE LOS CRIANCEROS SOBRE LA INTERVENCIÓN}

Respecto al diseño de la intervención, la principal evaluación positiva de los informantes entrevistados es que la inversión realizada contempló de buena forma los elementos infraestructurales necesarios para las plantas queseras (establecimiento, maquinarias, transporte). Para los crianceros que participaron, también resultó positivo que esta inversión inicial fuera asumida por el Estado, lo que fue un incentivo favorable para decidirse a participar. ción industrial: los crianceros de Río Hurtado y su experiencia en una planta quesera promovida por el Estado > Luis Pezo Orellana
La principal evaluación negativa del diseño por parte de los informantes es que no se tomaron en consideración las características socioculturales de los crianceros y las particularidades del territorio. No hubo un examen sobre los modos de producción y de vida de los crianceros que permitieran prever problemas y desarrollar una estrategia más adecuada de transformación productiva. Esta falta de compatibilidad sociocultural (Kottak, 1995) del diseño de la intervención, se sindica como una importante causal del fracaso del proyecto. Sobre las dificultades que en general pueden tener las intervenciones de desarrollo en poblaciones que se dedican al pastoreo, Kottak señala lo siguiente:

(...) no son sólo los objetivos excesivamente ambiciosos de muchos proyectos ganaderos los que hacen que el éxito sea improbable, también lo dificultan las características intrínsecamente complejas de estas poblaciones, cuando se contempla una vasta reestructuración social a corto plazo. Los pastores suelen vivir en áreas muy poco accesibles, escasamente pobladas y con un abastecimiento de agua deficiente. Son altamente móviles y evalúan constantemente los recursos disponibles, para las poblaciones humana y animal. Sus formas de organización se adaptan sutilmente a la vida por medio de un equilibrio sumamente delicado con su ambiente físico y ganadero, y los riesgos de trastornar esta adaptación por medio de cambios inapropiados o demasiado rápidos son elevados. Además, su vida transcurre en parajes tan remotos que las posibilidades de recopilar datos, supervisar, recaudar cuotas, aplicar las leyes y realizar tareas de monitoreo y evaluación son muy limitadas. Esta serie de factores dificulta, incluso para los especialistas experimentados en las ciencias sociales, cualquier predicción sobre el perfil de las intervenciones exitosas para el desarrollo (Kottak, 1995:510).

En efecto, el sistema extensivo de trabajo de los crianceros, que está adaptado a la geografía de la comuna, era incompatible con los requerimientos de la producción industrial. Los crianceros, en general, no estuvieron dispuestos a cambiar sus modos de vida y su forma de producción independiente, y al ausentarse para estar en las majadas ${ }^{5}$ (Figura 2), en los caseríos o para el traslado del ganado, no cumplieron con la demanda continua de leche de la planta, ni tampoco estuvieron presentes para la elaboración del queso u otras funciones que la empresa requería de sus socios. Terminaron desvinculándose del proyecto y volvieron a la producción del queso artesanal, que ya había recuperado su demanda en el mercado. Teniendo en cuenta las reconocidas dificultades planteadas por Kottak, estudios minuciosos habrían podido identificar los riesgos y diseñar una intervención más adecuada o bien sugerir formas alternativas de hacer frente a la crisis sanitaria de los quesos de cabra.

Es importante diferenciar la necesaria coherencia y adecuación de las intervenciones a las culturas locales (compatibilidad sociocultural), de la necesaria coherencia y adecuación con necesidades, intereses y perspectivas (incluyendo reivindicaciones) que pueda tener una población en un momento determinado, aspectos que pueden llevar consigo la pulsión de cambios, diferenciaciones o rupturas socioculturales, y que movilizan a las personas en la búsqueda de fines compartidos. Un proyecto puede ser compatible socioculturalmente, pero no guardar relación con los intereses locales. Esto último sólo se puede asegurar incorporando la participación de la gente desde la planificación misma de la intervención. 


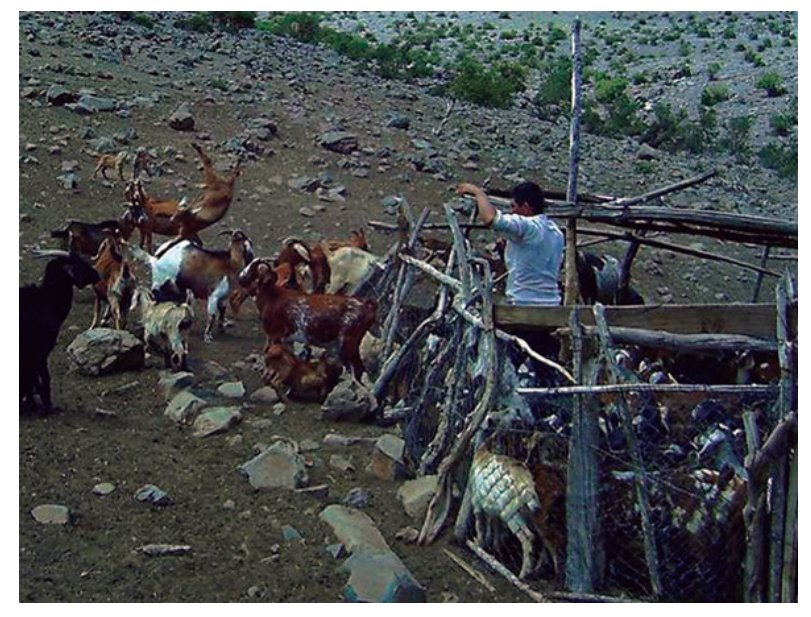

Figura 2. Majada del sector La Cortaderilla, Río Hurtado. En la imagen se ve la separación de cabras productivas de sus crías para la ordeña. Fuente: Stüdemann (2008).
En nuestro planteamiento, hay un criterio de pertinencia sociocultural cuando la intervención busca conseguir ambos aspectos.

En el caso de la quesera de Río Hurtado no se operó con este criterio, ya que además de la incompatibilidad sociocultural señalada, la intervención fue diseñada por actores políticos y técnicos a nivel regional y sólo contó con la participación de algunos representantes de los crianceros antes de su implementación. Tampoco se contemplaron monitoreos o evaluaciones de carácter participativo. El análisis de Durston et al. (2005) sobre otra planta quesera de la región señala una situación similar:

El modelo tradicional de intervención de INDAP no permitió el desarrollo de un proceso más horizontal. Sus intervenciones generalmente se gestionan de forma vertical $y$ su excesiva burocracia se tradujo en formas operativas impersonales, excesivamente normadas, sin considerar las condiciones locales y con poca interacción o retroalimentación de parte de la población objetivo. Generalmente los vínculos se establecían a través de representantes de comunidades y no con las bases. No existían diagnósticos participativos ni los funcionarios conocian las demandas más sentidas de la comunidad (Durston et al., 2005:123).

El verticalismo de la intervención también produjo confrontaciones entre el saber técnico y el saber local. Los crianceros comprobaron en los hechos que el saber técnico no siempre funciona bien en la práctica, ya que en algunos casos hay que ajustarlo a la realidad local y en otros resulta inoperante. En más de una ocasión el saber local de los crianceros permitió resolver problemas técnicos y optimizar la producción, no sin un grado de conflicto con los profesionales. El siguiente testimonio aborda una de estas diferencias, relativas a la extracción de leche de cabra (Figura 3)

(...) y dentro de eso hay hartas cosas que ni los técnicos lo saben, porque si usted es técnico me dice, "echa la cabra a comer y más rato sacas la leche”. ¿Sabe usted cómo sale la leche? Una cabra que vaya a comer y usted hace el queso después sale hediondo. El olor del tufo del pasto, del pasto verde. Nosotros exigíamos, bueno, yo puse la regla esa, que si quería vender leche, nosotros se la comprábamos pero que fuera leche sacada en la mañana. Que la cabra estuviera tranquila, descansada, y que cuando la gente se levantara sacara la leche. La leche llegaba a las seis o siete de la mañana, y salía un excelente queso, por qué, porque no tiene el olor a pasto, pero eso no es cuestión de la tecnología sino que es práctica de uno, es práctica de terreno. En cambio a mí me llaman tonto, porque me dicen que yo saco menos leche. En realidad es cierto, en la mañana dan menos leche las cabras, en cambio si usted las echa para el cerro en la mañana para que vayan a comer y después las rodea, puede sacar más leche, pero la leche no es buena. (...) Claro, entonces yo siempre he usado eso, yo todavía saco leche en la pura mañana, esté donde esté, en la cordillera o esté aquí, saco leche en la mañana. Después ando tranquilo en todo el día (Dirigente criancero que participó en la quesera).

Los testimonios recabados en nuestro estudio indican una percepción negativa del personal técnico como agente interventor, en tanto tendían a reproducir relaciones sociales de asimetría propias de un enfoque vertical de intervención, por un lado, y propias de ciertos prejuicios que subvaloran a los habitantes del sector rural, 
por otro. Es importante destacar que los crianceros se pronuncian críticamente contra ambos aspectos, y proponen un diálogo más horizontal, con mayor respeto y entendimiento.

Para todos los informantes entrevistados sin excepción, el proyecto de la planta quesera es concebido de manera general como un fracaso rotundo, una intervención que no funcionó, que no fructificó y que fue abandonada. Después de esta experiencia, la mayoría de los crianceros tiende a rechazar la industrialización del rubro, en primer lugar porque no corresponde a sus intereses y modos de vida (pertinencia sociocultural), y en segundo lugar porque dudan de su efectividad e impacto como estrategia de desarrollo. Lo anterior no sólo se debe a los serios problemas que debió enfrentar la Sociedad Agroindustrial Las Acacias y que la llevaron al fracaso, sino que también porque se visualiza la parcialidad de una estrategia regional que sólo incluía a un porcentaje menor de los crianceros de la región. Desde el principio, hubo crianceros que dudaron de esta intervención como una solución integral al problema del queso artesanal, ya que miles de familias de la región iban a ser afectadas por quedar excluidas de la conversión productiva:

Hasta ahí no creíamos nada, porque las queseras dentro de la provincia del Limarí fueron tres o cuatro, (...). No alcanzábamos a ser 100 personas en total, y los crianceros aquí somos más de 5 mil. Entonces la cesantía iba a ser muy grande... (Dirigente criancero que participó en la quesera).

Al constatar el carácter excluyente de esta intervención, y al cuestionarse la efectividad de la conversión productiva hacia el queso pasteurizado, varios crianceros han cuestionado los intereses del gobierno y han llegado a pensar, retrospectivamente, que los proyectos de las queseras no eran una "estrategia de desarrollo" sino que fueron más bien una "pantalla", un montaje político para responder a las presiones de otros actores que estaban en contra del queso artesanal y a favor de la imposición de la normativa de alimentos. Incluso algunos piensan que las intoxicaciones que desencadenaron la crisis también formaron parte de este montaje:

Las sospechas de los crianceros(...) se acrecentaron cuando poco tiempo después de esta grave crisis del rubro observaron cómo se impulsaba la tecnificación en la producción y grandes empresas (...) comenzaban a acaparar estos productos bajo el lema de dar confianza a sus consumidores. (...) En fin, los crianceros tienen enérgicas y fundadas sospechas acerca de que el escándalo de las intoxicaciones a principios de los '90 fue provocado a propósito por alguna "mano negra" que pretendía perjudicar la producción artesanal de quesos, a lo mejor en pos de industrializar el rubro (Stüdemann, 2003:20-21).

Bueno, las queseras del sur siempre son las que han querido aplastar este queso de cabra. Por eso es que dicen que eran las queseras del sur las que no querían que vendieran queso de cabra, eso comentaba la gente (Participante de la quesera).

Para (un criancero) la quesera de todos modos cumple una función. Es una especie de montaje frente a las autoridades para dar la impresión de que se está produciendo queso con leche pasteurizada (Stüdemann, 2003:24).

Estas percepciones son compartidas en otras comunas donde funcionaron las queseras, como lo señalan testimonios recogidos en el estudio de Durston et al. (2005:124).

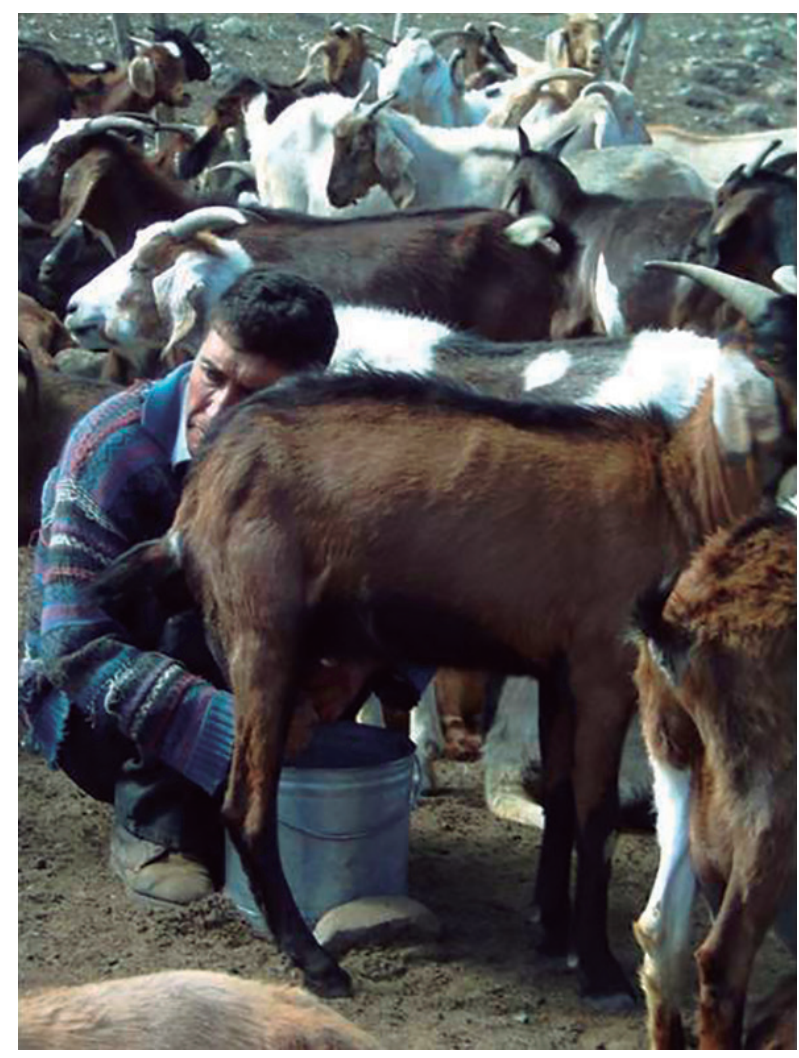


... a las autoridades les urgía que hubiera una planta y esta fue la primera planta que se creó bajo las nuevas normas sanitarias que entraron en vigor en mayo de ese año. Las autoridades querían tener una foto. (Pero la planta fue) una pantalla no más... se fueron y se alejaron de nosotros y hasta el momento (principios del 2000) estamos solos.

Se optó por el proyecto y rápidamente se dieron los recursos para esta construcción de la planta. Según todos los funcionarios se aplicaría (la ley, para suprimir la venta de queso rústico sin pasteurización)... y no ha sido así. ... yo como dirigente, me siento engañado por las autoridades.

En la bibliografía revisada existen evidencias de que ha habido fuertes presiones por parte de grupos económicos a las autoridades políticas para imponer la normativa sanitaria y sacar del mercado al queso artesanal de cabra. Cialdella (2003) señala que desde principios de los noventa han emergido grandes propietarios en la región de Coquimbo que han invertido en la producción industrial de queso pasteurizado, y que se han unido para presionar a las instituciones políticas con la prohibición de la venta de queso artesanal (Cialdella, 2003:347). En la siguiente cita se desarrolla la idea y las implicancias para los crianceros de la región que usan el sistema extensivo de producción, que la autora llama "trashumantes" 6 .

(...) los bajos precios del queso artesanal en la tempora da de invierno -temporada de producción de todos los sistemas productores de queso artesanal-, hacen bajar el precio del queso pasteurizado, por ello el objetivo del gran propietario es organizarse para que el queso artesanal desaparezca. Los trashumantes son los primeros ganaderos en conflicto con los productores de queso pasteurizado. El interés de estos últimos es la aplicación obligatoria de la ley sanitaria del proceso de los quesos, de esta manera, los sistemas trashumantes desaparecen, disminuyendo la actual competencia entre los productos queseros y aumentando la mano de obra para la producción de queso industrial (Cialdella, 2003:351).

Si bien nuestra investigación no nos permite confirmar las dudas, sospechas y conjeturas de los crianceros sobre los "intereses ocultos" tras los proyectos de las plantas queseras de la región, podemos afirmar que estas situaciones contribuyen a generar desconfianza hacia las autoridades de las instituciones públicas y de gobierno.

\section{EFECTOS DE LA INTERVENCIÓN SOBRE LAS PERSPECTIVAS DE DESARROLLO RURAL DE LOS CRIANCEROS}

De nuestra investigación se desprende que los impactos del proyecto en la ganadería caprina de Río Hurtado fueron prácticamente nulos, puesto que una vez que la iniciativa fracasó y se dejó de lado, los crianceros que participaron retornaron completamente al sistema extensivo y a la producción artesanal del queso de cabra, que por lo demás no habían abandonado del todo.

El queso artesanal ha recuperado su precio, y sigue siendo uno de los productos más vendidos de la zona. Los crianceros continúan enfrentando problemas típicos del sistema extensivo en la región: la sequía y la desertificación, los precios de los talajes, y las regulaciones sanitarias para la elaboración del queso y para el paso a Argentina.

En términos retrospectivos, la experiencia del proyecto estuvo lejos de incentivar la elaboración industrial de queso pasteurizado, sino más bien lo contrario: si antes los crianceros fueron renuentes a aventurarse en tal emprendimiento, ahora por lo general lo rechazan de plano. La gran mayoría de los informantes entrevistados en este estudio cree que un proyecto similar no resultaría y estaría destinado al fracaso. A lo anteriormente mencionado hay que agregarle la marcada desconfianza que tienen los crianceros en las instituciones y autoridades políticas, otro efecto de esta experiencia de intervención.

El rechazo de los crianceros a incorporarse en la producción industrial de queso pasteurizado nos lleva a sostener que no hubo una apropiación cultural de la iniciativa. Utilizamos este concepto siguiendo el esquema de Bonfil (1991) en el cual se plantea que existe una "cultura apropiada" cuando se practican decisiones propias sobre elementos culturales ajenos. Hasta cierto punto, el interés por la innovación utilizando recursos culturales ajenos se dio sólo excepcionalmente en el presidente de la planta quesera, quien aprendió los procesos vinculados a la producción industrial de queso pasteurizado, y en algunos momentos manifestó que a futuro podría realizar un emprendimiento de este tipo bajo condiciones distintas y en gran medida autocontroladas. Para el resto de los crianceros se aprecia una opción por la "cultura autónoma", vale decir, las decisiones propias se orientan a preservar elementos de la propia cultura, lo que se expresa en la tendencia a resistir la imposición de elementos culturales ajenos y a continuar con sus modos de vida.

No obstante, se debe reconocer que con el proyecto los crianceros aprendieron sobre nuevas técnicas de producción y nuevos modos de gestión, se reflexionó sobre la rentabilidad del queso tanto artesanal como pasteurizado, así como su comportamiento en los mercados, se aprendieron lecciones sobre los procesos de intervención, de participación y de vinculación con redes, se analizó críticamente la experiencia en su conjunto y se llegó a algunas conclusiones, entre las cuales sobresale el convencimiento de dedicarse a la elaboración de queso artesanal y de mantener sus modos de vida.

Los crianceros se orientan a defender un modelo de (su propio) desarrollo, que es distinto y antagónico al modelo impulsado por e Estado en la iniciativa que analizamos. La principal propuesta que plantean se orienta a incorporar regulaciones, controles y hábitos sanitarios que permitan el desarrollo de la producción artesanal de queso de cabra sin pasteurizar, según parámetros aceptables para su consumo.

\section{CONSIDERACIONES FINALES}

En el caso que hemos analizado, uno de los principales aspectos que se destaca es la falta de pertinencia sociocultural de la intervención, que junto a otros factores determinó el fracaso de esta iniciativa. Siguiendo un lineamiento clásico de la antropología aplicada, podríamos concluir este trabajo con una serie de recomendaciones para relevar la importancia de que las intervenciones sean socioculturalmente pertinentes, incorporando de manera temprana la participación de los sujetos sociales y que sean cohe rentes con las perspectivas de desarrollo de la sociedad civil en sus territorios. Por cierto, ello implica suponer que estos aspectos fueron descuidados por las autoridades y organismos públicos, cuyo verticalismo, tecnocracia y burocracia obnubilan las posibilidades de generar procesos más efectivos de desarrollo rural. Más 
aún, debiéramos reconocer distintas visiones de desarrollo rural y apuntar la necesidad de que la visión de los habitantes rurales sea considerada como primordial a la hora de decidir el camino a seguir en las intervenciones públicas, toda vez que el rumbo de las políticas gubernamentales puede ser cuestionable desde el punto de vista técnico e ideológico.

Sin embargo, nuestro estudio permite entrever un supuesto tras fondo político de esta intervención regional, que dice relación con presiones de actores económicos frente a las autoridades políticas, en donde poco importaría el desarrollo rural y su pertinencia sociocultural, y en donde la finalidad no sería el mejorar las condiciones sociales y productivas de las familias crianceras. En este escenario de relaciones de poder, volvemos nuestra mirada a los crianceros que luchan día a día por mantener sus sistemas de producción y de vida.

En la actualidad, el queso artesanal continúa con indeterminación legal, pese a significar el sustento y el consumo de miles de familias. En mayo de 2015, un reportaje del diario El Mercurio abordaba esta indeterminación legal entrevistando al especialista en quesos Manuel Zamora, del cual citaremos el siguiente extracto:

El Reglamento Sanitario de Alimentos, en su artículo 200, indica que "la pasteurización de la leche será obligatoria en aquellas localidades en que el Presidente de la República lo haya así decretado, de acuerdo a la Ley $N^{\circ} 4.869$ del 4 de agosto de 1930", lo que de acuerdo al especialista significa que "existirian localidades en que no sería obligatoria la pasteurización, y la Ley $N^{\circ} 4.869$ da a entender que dichas localidades serían las que no cuenten con plantas cercanas”. Más aún, el artículo 235 del RSA indica: "En aquellas localidades donde no rija la exigencia de la Ley $N^{\circ} 4.869$ de pasteurización de la leche, todos los quesos deberán tener un período de maduración previo no menor a 30 días para su comercialización" (EI Mercurio, Revista del Campo, lunes 18 de mayo de 2015).

De esta cita, se destaca el hecho de que la elaboración de quesos con leche cruda no estaría estrictamente prohibida por la normativa sanitaria, pero que ella se restringe a ciertas localidades que no están definidas, pero que serían aquellas "que no cuenten con plantas cercanas". Con esta disposición legal, surge inevitablemente una conexión entre una estrategia regional para instalar plantas queseras en zonas rurales (donde antes no las había) y la prohibición de la elaboración de queso de cabra sin pasteurizar. En consecuencia, se puede pensar que las plantas queseras no sólo provocarían la transformación productiva de los socios que decidieran aventurarse en ella, sino también de los productores "cercanos", de aplicarse estrictamente esta disposición legal.

En el reportaje señalado se indica que en muchos países de tradición quesera, las leyes sanitarias son estrictas, pero permiten la elaboración de quesos con leche cruda, entendiendo que la flora microbiana natural de la leche es un ingrediente esencial para lograr sabores, aromas y texturas distintivas, constituyendo también la característica de varios quesos con Denominación de Origen. Por ello subraya la necesidad de actualizar el Reglamento Sanitario de Alimentos y la Ley $\mathrm{N}^{\circ} 4.869$-que data del año 1930-, aspecto con el cual estamos plenamente de acuerdo. Al respecto, creemos pertinente considerar la propuesta de Cialdella (2003:355), quien plantea que es necesario considerar también la coexistencia de los dos tipos de quesos: pasteurizado y artesanal, ya que no tienen el mismo tipo de consumidores y tampoco el mismo gusto. La autora concluye poniendo en tela de juicio si ambos tipos de queso son realmente -o necesariamente- productos en competencia.

\section{BIBLIOGRAFÍA}

BAHAMONDES, M. (2004) Poder y reciprocidad en el mundo rural: un enfoque crítico a la idea de capital social, Santiago: GIA - Universidad Academia de Humanismo Cristiano.

BONFIL, G. (1991) Pensar nuestra cultura, México: Editorial Patria.

CASTILLO, G. (2003) “La vuelta de los años: reseñas y perspectivas sobre las comunidades, el pastoreo y la trashumancia en la región semiárida de Chile", en: Livenais y Aranda (Eds.) Dinámicas de los sistemas agrarios en Chile árido: la región de Coquimbo, Santiago: LOM.

CIALDELLA, N. (2003) "Diversidad de los sistemas de producción caprina y perspectivas de evolución en la región de Coquimbo", en: Livenais y Aranda (Eds.), Dinámicas de los sistemas agrarios en Chile árido: la región de Coquimbo, Santiago: LOM.

CONTRERAS, R., CHAMORRO, A. y DONOSO J. P. (2004) Diagnóstico sociocultural sobre la participación de las organizaciones sociales en acciones de intervención social de lucha explícita contra la desertificación y la pobreza en tres localidades del valle medio de Río Hurtado. Informe Final, Grupo de Estudios Rurales, Universidad de Chile, manuscrito, disponible en: www.elcanelo.cl/nweb_portal/pics/ documentos/10/publ_final_eva2004_rio_hurtado.pdf

DURSTON, J., DUHART, D., MIRANDA, F. y MONZÓ, E. (2005) Comunidades campesinas, agencias públicas y clientelismos políticos en Chile, Santiago: LOM - Grupo de Investigaciones Agraria (GIA).

KOTTAK, C. Ph. (1995) Cuando no se da prioridad a la gente. Algunas lecciones sociológicas de proyectos terminados, en: Cernea, M. (ed.) Primero la gente. Variables sociológicas en el desarrollo rural, México: Fondo de Cultura Económica.

KOTTAK, C. Ph. (2002) Antropología cultural, Madrid: McGraw-Hill.

ORTIZ, S. (1979) Reflexiones sobre el concepto de la "cultura campesina" y los "sistemas cognoscitivos campesinos", en: Shanin, T. (Comp.) Campesinos y sociedades campesinas, México: Fondo de Cultura Económica.

PEÑA, D. (2006) Desarrollo rural: implicancias y significados desde la perspectiva de sus habitantes. El caso de las comunidades agrícolas de Carquindaño y Yerba Loca, Comuna de Canela, IV región, Chile, Tesis Magíster en Antropología y Desarrollo, Facultad de Ciencias Sociales, Universidad de Chile, Santiago.

PEZO, L. (2010) Sociedad civil y desarrollo rural: trayectorias de participación social en la comuna de Río Hurtado (19902008), Tesis para optar al grado de Magíster en Antropología y Desarrollo, Universidad de Chile, Santiago.

RACZYNSKI, D. y SERRANO, C. (1998) Lineamientos para construir una matriz de indicadores de participación social en programas nacionales participativos. Informe final de 
consultoría, Santiago: Asesorías para el Desarrollo, 1998, disponible en: http://www.asesoriasparaeldesarrollo.cl/ docs/822774485.pdf

RAMÍREZ, I. (2003) Evolución y perspectivas de la producción caprina en la IV Región de Coquimbo, en: Livenais y Aranda (Eds.) Dinámicas de los sistemas agrarios en Chile árido: la región de Coquimbo, Santiago: LOM.

REVISTA DEL CAMPO (lunes 18 de mayo de 2015) Falta claridad en la normativa. Reportaje de Arnaldo Guerra Martínez, disponible en: http://diario.elmercurio.com/detalle/index. asp? id $=\{$ acce 77 ec-fOf5-4c0f-956f-925617f27eda $\}$

STÜDEMANN, N. (2003) Crianceros de ganado caprino. Una aproximación a los productores en la localidad de Pichasca y la entidad El Chacay. Informe de Avance, Cátedra de Antropología Rural, Departamento de Antropología, Universidad de Chile, manuscrito.

STÜDEMANN, N. (2008) Producción caprina en el valle de Río Hurtado. Una mirada antropológica, Memoria para optar al título de Antropólogo Social, Facultad de Ciencias Sociales, Universidad de Chile, Santiago.

STÜDEMANN, N. (2010) Producción caprina tradicional. Perspectivas y reflexiones desde la antropología, en: Hernández, R. y Pezo, L. (Eds.) La ruralidad chilena actual. Aproximaciones desde la antropología, Santiago: CoLibris, pp. 325-364.

UPHOFF, N. (1995) Adaptar los proyectos a la gente, en: Cernea, M. (ed.) Primero la gente. Variables sociológicas en el desarrollo rural, México: Fondo de Cultura Económica.

\section{NOTAS}

1 Un interesante examen de estos procesos de cambio desde una perspectiva histórica y etnográfica se puede ver en Castillo (2003).

2 Con "oportunidad impuesta" nos referimos a una propuesta de desarrollo diseñada por un agente externo de acuerdo a sus propios criterios, que ofrece una solución predeterminada para atender o enfrentar un determinado problema.

3 De acuerdo a Raczynski y Serrano (1998), la participación gestionaria es aquella que genera capacidades en la comunidad y supone la existencia de liderazgo social e información para actuar como interlocutor de agencias locales y estatales. Supone una influencia mayor en la toma de decisiones, pues los destinatarios son considerados como gestionadores de programas estatales.

4 Existen antecedentes empíricos que indican que cuanto mayor es el ingreso de un agricultor, mayor es su inclinación a aceptar innovaciones y asumir riesgos (Ortiz, 1979).

5 Las majadas son pequeñas viviendas rústicas que sirven de refugio para los crianceros y para la elaboración de queso en zonas aisladas de alta montaña, las cuales disponen de al menos un corral para el ganado (Stüdemann, 2008).

6 Para la autora citada, la trashumancia, que se puede definir resumidamente como el traslado estacional del ganado hacia zonas altas (veranada) y bajas (invernada) en busca de praderas para el pastoreo del ganado, es un aspecto central de los crianceros de la región de Coquimbo cuyo sistema de producción es de tipo extensivo. No obstante, cabe mencionar que Stüdemann (2010) proporciona una interesante discusión del concepto de trashumancia, planteando que es insuficiente para describir la complejidad de formas de traslado del ganado que realizan los crianceros que observó en Río Hurtado. 